\title{
Hawthorn (Crataegus spp.) from botanical source to phytopreparations
}

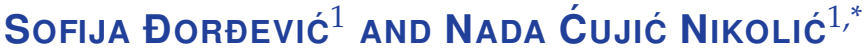 \\ ${ }^{1}$ Institute for Medicinal Plants Research "Dr. Josif Pančić”, Tadeuša Košćuška 1, 11000 Belgrade, Serbia \\ *Corresponding author: ncujic@mocbilja.rs
}

Published: December 25, 2021

Received: September 14, 2021

Accepted: December 12, 2021

Published on-line: December 15, 2021

\begin{abstract}
The usage of hawthorn preparations has a long history in the traditional treatment of heart failure, which is considered as the inability of a weakened heart to supply peripheral tissues with the required amount of oxygen and nutrients. The leaf, flower, and fruit of the hawthorn, due to the presence of bioactive compounds such as flavonoids, procyanidins, organic acids, amines, etc., are showing a wide range of the effects on the cardiovascular system. The leaf and flower have a positive monograph in Commission E, as well as the EMA monograph, but only for traditional use. Numerous clinical studies have been conducted to evaluate the beneficial effects of dry hawthorn extracts on heart diseases. There are a large number of phytopreparations in various galenic forms on the market trade. According to the recent guidelines, usage of hawthorn preparations as a monotherapy in heart failure is not recommended. Instead, it should be used as an adjunct therapy.
\end{abstract}

Key words: Crataegus, C. monogyna, C. oxyacantha, cardiotonics, heart failure, phytopreparations

http://dx.doi.org/10.5937/leksir2141063D

\section{HISTORY AND TRADITIONAL USE}

The use of medicinal plants in the prevention and alleviation of many diseases has been known from the existence of humanity. Medicinal herbs have been a source of food and medicine from ancient times, due to the presence of valuable bioactive compounds. In primary health care around the world, medicinal plants are demonstrating great importance. Studies reported by the World Health Organization (WHO), have shown that around $80 \%$ of the world's population is using herbs to prevent or treat a wide range of diseases (Arslan and Bektas, 2018; Djordjevic, 2017; Yusuf and Mericli, 2016).

Hawthorn has been well-known as an extremely important and valued medicinal plant. Hawthorn leaf, flower, and fruit, as well as their preparations, have a long history in the prevention and treatment of heart failure. In Europe, hawthorn has been mentioned as a herbal medicine for the first time in the $1^{\text {st }}$ century AD, by Dioscorides, who has been considered as the founder of European pharmacopoeia, author of the capital work De Materia Medica. Practically, since that time, hawthorn has been an integral part of the traditional medicine of many nations as medicine for strengthening a weakened heart (Holubarsch et al., 2018; Kaul, 1998). For many centuries, hawthorn has been used as a tonic for better circulation and for improving the functionality of other organs. In the second half of the $19^{\text {th }}$ century, this plant became known as a cardiac medicine, due to an Irish doctor Green, who successfully treated many heart problems using hawthorn. Since then, it has been an integral part of cardiotonic phytopreparations (EMA, 2016a; Tassell et al., 2010). Comprehensive scientific trials, which included the clinical effects of hawthorn preparations, have begun since the thirties of the last century (Holubarsch et al., 2018).

Various traditional uses of herbal drugs and preparations of hawthorn flowers, leaves, and fruits have been recorded. In German folk medicine, flower tea was recommended as a tonic for the heart in the elderly age, in the treatment of arteriosclerosis, and for high blood pressure. In Polish folk medicine, the hawthorn flower has been used as a sedative, in Hungary for the treatment of jaundice and as a remedy against constipation. In the Czech Republic and Slovakia, hawthorn flowers have been used to treat coughs, urinary tract ailments, and as a warm compress to relieve pain. At the beginning of the $20^{\text {th }}$ century, hawthorn was also used in America for the treatment of various heart problems, angina pectoris, as a tonic for the heart treatment, for the regulation of circulation, alleviation of cardiac neuroses, and digestive problems. In traditional Chinese medicine, hawthorn has been primarily used to improve poor circulation, hypertension, dyspnea, digestion problems, and often for nutritional purposes. In Israel and neighboring Arab countries, hawthorn has been used in heart failure, diabetes, and cancer prevention and treatment (EMA, 2016a; Yusuf and Mericli, 2016). According to the Comision E monograph, in traditional medicine, hawthorn has been used as a cardiotonic, in hypertension, cardiac arrhythmia, 
cardiac ischemia, as a sedative, and has shown some efficiency in reducing cholesterol (Blumenthal, 1998; PDR, 2000).

In Serbian traditional medicine, hawthorn preparations have been used as cardiotonics, antispasmodics, geriatrics (Sarić, 1989). According to Tucakov (1996), the flower and leaf of hawthorn have been used for patients with heart and nervous diseases and women in menopause. It has been given for initial heart failure, weakened myocardium after mild infectious diseases (e.g., influenza), and other heart problems in the elderly age.

\section{BOTANICAL CHARACTERISTICS}

The name of the genus Crataegus L. comes from the Greek word krataios which means solid. It was derived from the ancient name of krataigos, which denoted a species of this genus (C. azarolus) from the eastern Mediterranean. Names for hawthorn in other languages: Russian - боярышник, глод, English - hawthorn, whitethorn; German - Wei $\beta$ dorn, Hagedorn; French - aubepine, epine blanche, Serbian - glog, gloginja, gloginjka, glogovka (Konjević and Tatić, 2006; Simonović, 1959).

Genus Crataegus L. belongs to the family of roses Rosaceae. The family Rosaceae includes about 3300 species, distributed to a greater extent in the northern hemisphere. These are herbaceous annuals and perennials, deciduous or evergreen trees, and shrubs. The species also belong to ornamental plants such as roses or fruit trees. The leaves are simple or differently arranged, with valves. The flowers are solitary, in clusters. The fruits are in aggregate as a stone fruit or pomum (Jančić and Lakušić, 2017).

According to the European Flora, the family Rosaceae consists of four subfamilies: Spiraeoideae, Rosoideae, Maloideae, and Prunoideae. In Flora SR Serbia, these subfamilies are presented as independent families: Spiraeaceae, Rosaceae, Malaceae, and Amygdalaceae. Species of the genus Crataegus belong to the subfamily of Maloideae (Jančić and Lakušić, 2017; Josifović, 1972; Tutin et al., 1968).

Species of the genus Crataegus L. are deciduous, most often thorny shrubs or low-growing trees. The leaves are alternate, lobed to pinnately cut, simple or double serrated, or with a whole rim. The flowers are small, arranged in rich clusters. Five calyx leaves are short, triangular, drooping, or remaining on the fruit. Five coronal leaves are round, usually white, rarely pink. The flowers develop at a time when the leaves have not reached normal size. The fruit is pomum, stone-shaped, red, black or orange (Jančić and Lakušić, 2017; Josifović, 1972).

The genus is very rich in species, varieties, and hybrids. The genus Crataegus is estimated to have about 300 species worldwide and abounds of many varieties and hybrids as well (Tassell et al., 2010). According to the Flora of SR Serbia (Josifović, 1972), the genus Crataegus L., contains 8 species, as follows:

- C. crus-galli L. - thorny hawthorn

- C. monogyna Jacq. - single-seeded white hawthorn

- C. calycina Peterm. - cupped hawthorn

- C. oxyacantha L. - red hawthorn

- C. pentagyna Wald. et Kit. - five-stemmed hawthorn

- C. nigra Wald. et Kit. - black hawthorn

- C. heldreichii Boiss. - Heldreich's hawthorn

- C. laciniata Ucria - eastern hawthorn

In the supplemented edition of Flora SR Srbije, volume $X$ appendix 2 (Sarić, 1986), C. monogyna Jacq., the single-seeded white hawthorn is containing two varieties: var. monogyna f. dissecta (C. dissecta) and var. microphylla. According to Flora Europaea (Tutin et al., 1968), the genus Crataegus has 22 species.

The most commonly used hawthorn species in Europe are white hawthorn, Crataegus monogyna Jacq. (Lindm.) and red hawthorn, Crataegus laevigata (Poir.) DC. (syn. C. oxyacantha L.).

Crataegus monogyna Jacq. - white hawthorn (syn. Mespilus monogyna All.) is a deciduous shrub or low tree. The twigs are bare or slightly hairy, with thorns around $1 \mathrm{~cm}$. The leaves are deeply incised and divided into lobes. The flowers are small, gathered in a multi-flowered straight inflorescence cluster, and contain 5 calyxes and 5 coronal leaves, white or light pink color. The fruit is a red stone (pomum) with one seed-stone, broadly ovoid, size around 5-10 mm (Figure 1). It is widespread most often in xerothermic oak forests of Europe, Asia, and North America (Sarić, 1989; Tasić et al., 2009).

Crataegus oxyacantha L., red hawthorn is a shrub or lowgrowing tree. Young branches are slightly hairy, later become bare, with thorns up to $2.5 \mathrm{~cm}$. Opposite to the white hawthorn, the leaves of red one are shallowly cut, slightly serrated around the rim and lobed. Inflorescences are consisting 6 to 8 flowers. The coronal leaves are white or reddish. The fruit is a stone with 2 to 3 seeds (Figure 2). Red hawthorn blooms in May just before C. monogyna and it is much more sensitive to the continental climate than previously mentioned species (Josifović, 1972; Sarić, 1989).

\section{HERBAL DRUGS AND EXTRACTS}

\subsection{Biological sources of drugs}

The European Pharmacopoeia (Ph. Eur., 2014a), and the German Pharmacopoeia (DAB 10, 1993) recommended in addition to previously mentioned biological sources, three other European Crataegus species:

- C. azarolus L., (tame hawthorn) is a tall tree without thorns, with lobed leaves, white flowers and yellow or orange-red fruits.

- C. nigra Waldst. et Kit., (black hawthorn) has black fruits and hairy leaves along the nerves.

- C. pentagyna Waldst. et Kit., (five-stemmed hawthorn), is a tree or shrub, with long thorns, lobed, hairy leaves on the back side, with dark red fruits.

As a biological source for leaf and flower of hawthorn, the Swiss Pharmacopoeia (Ph. Helv. VIII, 1997) and the French Pharmacopoeia (PF X, 1982) recommended only C. monogyna Jacq. and C. oxyacantha L.

The biological source for hawthorn fruit (Crataegi fructus) according to Ph. Eur. (2014b) and the ESCOP (2009), are only two species of C. monogyna and C. laevigata (C. oxyacantha L.) and their hybrids.

\subsection{Officinal herbal drugs}

The following monographs of herbal drugs have been published in Ph Eur:

1. Crataegi folium cum flore, hawthorn leaf and flower (Ph. Eur., 2014a): "Definition: whole or cut, dried flowerbearing branches of C. monogyna Jacquin (Lindman), C. laevigata (Poiret) DC. (syn. C. oxyacanthoides Thuill.; C. oxyacantha auct.), or their hybrids or, more rarely, other European Crataegus species including C. pentagyna Waldstein et Kitaibel ex Willdenow, C. nigra Waldstein et Kitaibel and C. azarolus L.". 

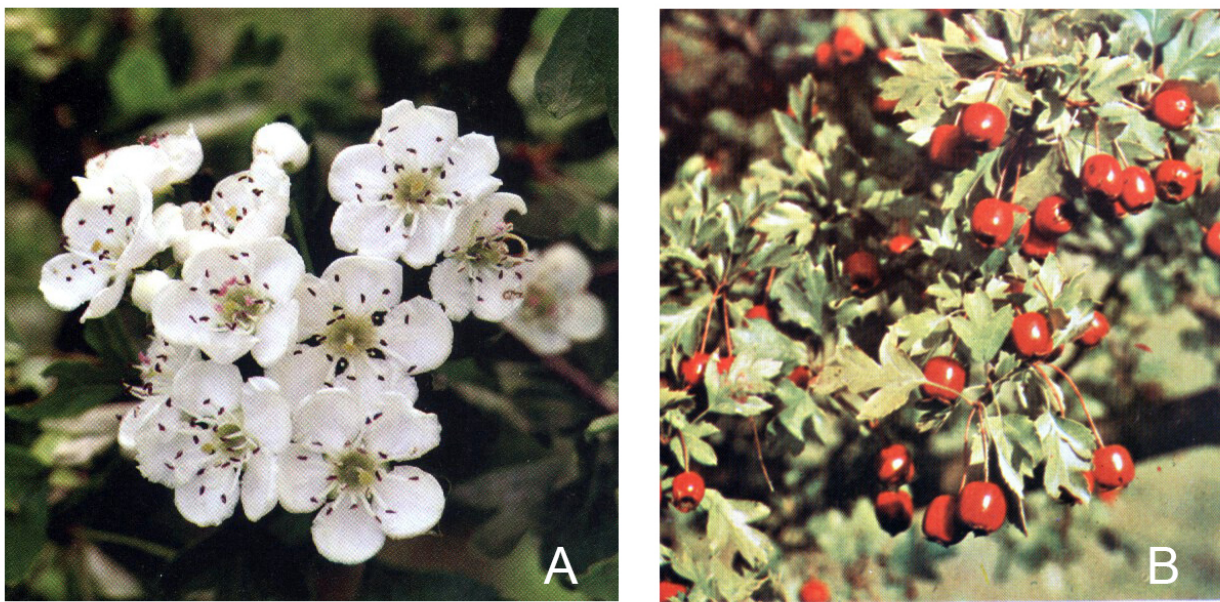

Fig. 1. Hawthorn (Crataegus monogyna); A - leaves with flowers (Stojanović, 2013); B - fruits (Šilić, 1990).
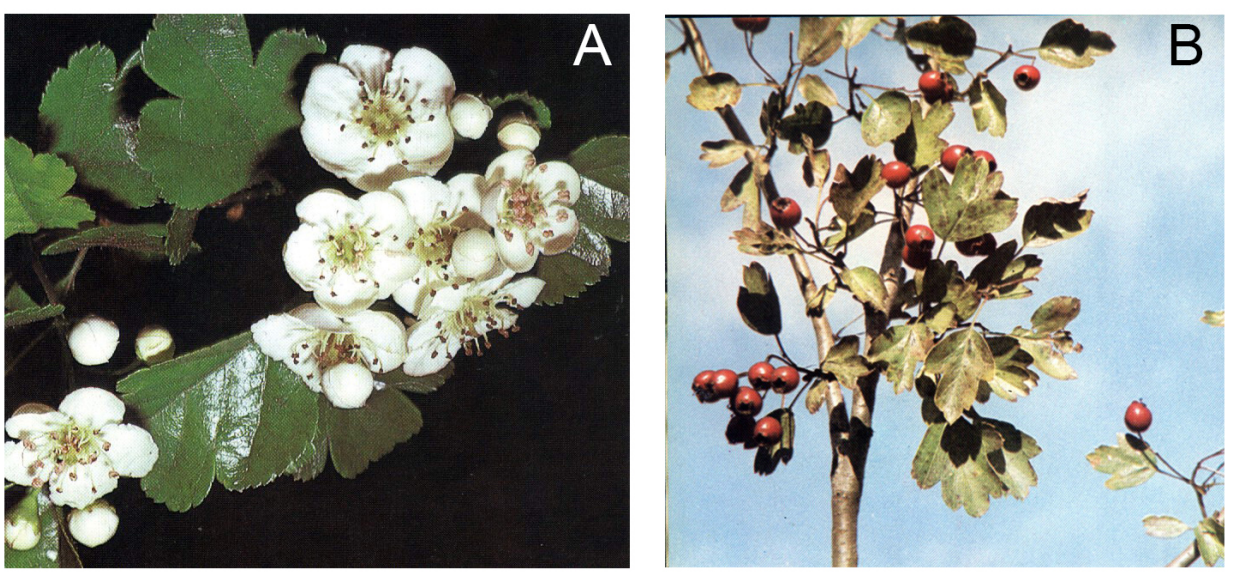

Fig. 2. Red hawthorn (Crataegus oxyacantha); A - leaves with flowers (Lanzara and Pizzetti, 1982); B - fruits (Šilić, 1990).

2. Crataegi fructus, hawthorn berries (Ph. Eur., 2014b): "Definition: Dried false fruits of C. monogyna Jacq. (Lindm.) or C. laevigata (Poir.) DC. (syn. C. oxyacantha L.) or their hybrids or a mixture of these false fruits".

Hawthorn-based phytopreparations can be made from several herbal drugs, such as leaf, flower, and fruit, which are officinal in Europe, as mentioned in many national pharmacopoeias:

- leaves with flowers, Crataegi folium cum flore according to Ph. Eur. (2014a) contains a minimum of $1.5 \%$ flavonoids, calculated as hyperoside; according to DAB 10 (1993) minimum of $0.7 \%$ flavonoids, calculated as hyperoside; according to (Ph. Helv. VIII, 1997) min. $0.6 \%$ C-glycosylflavones, calculated as a vitexin;

- flowers, Crataegi flos minimum of $0.7 \%$ flavonoids, calculated as hyperoside (Hänsel et al., 1999);

- fruits, Crataegi fructus according to Ph. Eur. minimum of $0.06 \%$ procyanidins, calculated as cyanidin chloride (Hänsel et al., 1999; Ph. Eur., 2014a;b).

Crataegi folium cum flore and/or Crataegi fructus is also described in several Pharmacopoeias (British, Chinese, American), as well as "Crataegi flores" by Russian (Sagaradze et al., 2019; Tasić et al., 2009).

\subsection{Officinal extracts}

Two herbal extracts are also official in the European Pharmacopoeia (Ph. Eur., 2014c;d):

- Crataegi folii cum flore extractum siccum - dry extract produced from hawthorn leaf and flower. "Content: for aqueous extracts minimum $2.5 \%$ of total flavonoids, expressed as hyperoside and for hydroalcoholic extracts minimum $6.0 \%$ of total flavonoids, expressed as hyperoside. The extract has been produced from the herbal drug by a suitable procedure using water or a hydroalcoholic solvent $(45 \% \mathrm{~V} / \mathrm{V}) "$

- Crataegi folii cum flore extractum fluidum quantificatum quantified liquid extract of hawthorn leaf and flower. "Content: $0.8-3.0 \%$ of flavonoids, expressed as hyperoside. The extract has been produced from the herbal drug and ethanol (30-70 \% V/V), according to the appropriate procedure".

In the German Pharmacopoeia, the liquid extract (Crataegi extractum fluidum) is officinal, standardized to $0.25-0.5 \%$ of flavonoids, calculated as hyperoside (DAB 10, 1993).

According to the Swiss Pharmacopoeia (Ph. Helv. VIII, 1997), the hawthorn dry extract (Crataegi extractum siccum normatum) is officinal, standardized to $0.8-1.2 \%$ of flavonoids. 


\subsection{Representation in monographs}

In 1994, German Commission E issued positive monographs of hawthorn leaves and flowers for the treatment of declining functional capacity of the heart, which corresponds to the class II functional classification of the New York Heart Association (NIHA). This is characterized as mild cardiac symptoms such as fatigue, palpitations, dyspnea, or anginal pain during normal activity (AHA, 1994; Blumenthal, 1998; Holubarsch et al., 2018). Commission E positively evaluated only hawthorn leaves and flowers, as well as the appropriate combinations of flowers, leaves, and fruits.

Crataegus folium cum flore as a herbal drug are found in the monographs: German Commission E (Blumenthal, 1998), EMA (2016b), and WHO (2002). Crataegi folium cum flore and fructus are described in Herbal Drugs and Phytopharmaceuticals (Bisset and Wichtl, 2001) and ESCOP (2003; 2009). Only English hawthorn Crataegus levigata is presented in the PDR for Herbal Medicines (PDR, 2000).

\section{CHEMICAL COMPOSITION}

The chemical composition of leaves, flowers, and fruits of hawthorn Crataegus spp. is similar but it differs in the content of individual ingredients (Figure 3). According to pevious reports (Bradley, 2006; Edwards et al., 2012; EMA, 2016a; Hänsel et al., 1999; Kumar et al., 2012; Petrović, 2003; WHO, 2002) the main compounds of these herbal drugs are:

- flavonoids (mainly in the form of $\mathrm{O}$ and C-glycosides) - hyperoside, rutin, spiraeoside, vitexin, vitexin-2-Orhamnoside, isovitexin, orientin. In Crataegi folium cum flore flavonoids are in the range of 0.3-2.5\%, and Crataegi fructus $0.05-0.15 \%$.

- flavan compounds (e.g. (+)-catechin, (-)-epicatechin, oligo- and polymeric procyanidins). In the flower and leaf procyanidins are present $1-4 \%$, and in the fruit 0.4-2.9 $\%$.

- organic acids (caffeic acid, chlorogenic acid).

- triterpenic acids (oleanolic acid, crataegolic acid, ursolic acid)

- biogenic amines (phenethylamine, acetylcholine, ethylamine).

- other constituents (purine derivatives, minerals, mainly potassium salts, sterol).

The total content of phenolic compounds is higher in leaves and flowers compared with fruits. Procyanidins are dominant in fruits, while flavone glycosides and C-glycosylic flavones are most prevalent in leaves. The fruit contains more minerals, sugars, organic acids, anthocyanins, carotenoids, vitamin C (Kovačević, 2002).

According to Yang and Liu (2012),

- C. monogyna (Europe) contains:

- Leaf: Flavonols (hyperoside, rutin, isoquercitrin), C-glycosyl flavones (vitexin, 4"-acetylvitexin-2"-Orhamnoside, isovitexin, vitexin-2"-O-rhamnoside), other phenolics (chlorogenic acid).

- C. laevigata (Europe) contains:

- Fruit: Procyanidins (epicatechin; dimer: B2, B4, B5; trimer: $\mathrm{C} 1$, tetramer: $\mathrm{D} 1$; pentamer: epicatechin units linked through C- $4 \beta /$ C- 8 bonds).

- Leaf: Procyanidins (epicatechin; dimer: B2, B4, B5; trimer: C1, tetramer: D1; pentamer: epicatechin units linked through C-4 $\beta / C-8$ bonds)
Flavonols (hyperoside, rutin, isoquercitrin). Cglycosyl flavones (isovitexin, vitexin, acetylvitexin2"-O-rhamnoside, vitexin-2"-O-rhamnoside). Other phenolics (caffeic acid, chlorogenic acid).

- Flower: Procyanidins (epicatechin; dimer: B2, B4, B5; trimer: C1, tetramer: D1; pentamer: epicatechin units linked through C- $4 \beta /$ C- 8 bonds). Flavonols (hyperoside, rutin, isoquercitrin).

\subsection{Chemical assays}

According to the German Pharmacopoeia (DAB 10, 1993), the content of flavonoids, calculated as hyperoside for the drug Crataegi folium cum flore and liquid extract Crataegi extractum fluidum, was determined by spectrophotometric method. The European Pharmacopoeia (Ph. Eur., 2014a;c;d) prescribes the same method for Crataegi folium cum flore, Crataegi folii cum flore extractum siccum and Crataegi folii cum flore extractum fluidum quantificatum, but in some difference of sample preparation for photometric measurement. For Crataegi fructus, the Ph. Eur. (2014b) prescribes spectrophotometric determination of procyanidins content, expressed as cyanidin chloride.

Analytical methods such as colorimetric, HPLC (combined with ultraviolet detection or mass spectrometry), and capillary electrophoretic have been used to determine the content of phenolic compounds in hawthorn (Yang and Liu, 2012).

The $\mathrm{H}^{1} \mathrm{NMR}$ analysis of four flavonoids (hyperoside, rutin, naringenin, and vitexin-2"-O-rhamnoside) and chlorogenic acid (data compared with HPLC-DAD analysis) from leaf extracts of four Crataegus species, growing in Europe and North America, showed that vitexin and its derivatives were significantly more concentrated in the leaves of European species of hawthorn (C. monogyna and C. laevigata), and rutin was significantly more concentrated in the leaves of North American $(C$. douglasii and C. okanaganensis). The concentrations of rutin and naringenin in the examined Crataegus species were the highest (Lund et al., 2020). Sagaradze et al. (2019) examined the variability of rutin, vitexin, hyperoside, quercetin in Crataegi folium cum flore in European species of the genus Crataegus, with the addition of the genus Sanguineae species, growing in the Asian region of Russia. Analysis of these compounds was performed by the HPLC-UV method. Hyperoside was the predominant compound in all species and ranged from 1.55 (C. nigra) to $12.59 \mathrm{mg} / \mathrm{g}$ (C. monogyna). Rutin ranged from 0.35 to $5.37 \mathrm{mg} / \mathrm{g}$, vitexin from 0.52 to $3.90 \mathrm{mg} / \mathrm{g}$. There were no significant differences in concentrations of examined compounds between species of the genera Sanguineae and Crataegus, while the content of vitexin was higher in species of the genus Sanguineae.

Muradoğlu et al. (2019) examined the chemical composition of four Crataegus species fruits. Fructose and glucose were the predominantly presented sugars. Rutin, catechin, and caffeic acid were the dominant phenolic compounds in all tested species. The great variability of sugars, vitamins, organic acids, and phenolic components between genotypes of the same species was observed. Vitamin $C$ contents of $C$. monogyna subsp. monogyna ranged between 21.8 and $34.4 \mathrm{mg} / 100 \mathrm{~g}$ Analyzing the chemical composition of the fruit C. monogyna var. monogyna, Dokumac1 et al. (2021) found that the hawthorn fruit is very useful for human consumption, due to the presence of protein, fatty oil, as well as a significant amount of total phenols, and important minerals $(\mathrm{K}, \mathrm{P}, \mathrm{Ca}, \mathrm{Mg}$, Fe, $\mathrm{Na}$ and B).

In order to examine the hawthorn fruit beneficial ingredients, which could be used in the diet, soluble carbohydrates, total carotenoids, total phenols, and the content of flavonoids, minerals, etc. were determined, among others. Fruit samples of 15 different hawthorns (Crataegus spp.) species from differ- 
<smiles></smiles>

Hyperoside<smiles>O=c1cc(-c2ccc(O)cc2)oc2c(C3O[C@H](CO)[C@@H](O)[C@H](O)[C@H]3O)c(O)cc(O)c12</smiles>

Vitexin<smiles>Oc1cc(O)c2c(c1)O[C@H](c1ccc(O)c(O)c1)[C@H](O)[C@H]2c1c(O)cc(O)c2c1O[C@H](c1ccc(O)c(O)c1)[C@@H](O)C2</smiles>

Procyanidin B2

Fig. 3. Dominant compounds in Crataegus spp.

ent regions of Iran were examined. A significant content of tested ingredients, valuable for the pharmaceutical and food industry was determined (Alirezalu et al., 2020).

\section{INDICATION AND USE}

\subsection{Heart failure}

As it was previously mentioned, the hawthorn flower, leaf, and fruit, as well as their phytopreparations are intended as an adjunct therapy for heart failure. Cardiovascular diseases are disorders of the heart functionality as well as blood vessels that supply blood to the heart and other organs. The most usual cardiovascular disorders are coronary heart disease, heart failure, stroke, arterial hypertension, peripheral artery disease. Cardiovascular diseases account for about 17 million deaths annually worldwide (Cloud et al., 2020).

Heart failure (HF) is one of the most difficult diagnoses in medicine (McMurray et al., 2012), and can be defined as cardiac structure or function abnormality to enable the heart to deliver oxygen to the tissues, despite normal filling pressures. Clinically, patients with HF have typical symptoms of breathlessness, ankle swelling (McMurray et al., 2012).

The most common causes of systolic HF are ischemic heart disease (myocardial infarction and angina pectoris), hypertension, diabetes, cardiomyopathy (dilatation and hypertrophy), arrhythmia, congenital or acquired heart valve disease, and pericardial disease. Rarely, the causes can be viral infections, anemia, hyperthyroidism, excessive alcohol use, some medications, etc. The most common causes of diastolic HF are hypertension, coronary heart disease, absolute arrhythmia, cardiomyopathies, fibrosis, etc. Heart failure is mainly a disease of the elderly (Stepanović-Petrović and Micov, 2011).

The most commonly used method for the chronic HF classification is the New York Heart Association (NYHA) functional classification system, a classification based on the presentation of symptoms (AHA, 1994). HF classification according to NYHA:

- Class I: the patient has no restrictions on physical activity and it does not lead to fatigue, suffocation, or palpation.

- Class II: less restriction of physical activity, the patient feels good at rest, but normal activities cause fatigue, suffocation, or palpation.

- Class: III: the patient has a significant limitation of physical activity, feels good at rest, but small normal activities lead to fatigue, suffocation, or palpitation.

- Class IV: problems that appear or symptoms of HF are present at rest and any physical activity increases discomfort.

Treatment of HF is carried out with:
- non-pharmacological measures, lifestyle changes (smoking cessation, limited alcohol intake, physical and mental relaxation, avoiding of high temperatures and hard physical work, weight loss, reduced sodium intake, increased potassium intake, avoiding of full-fat and difficult to digest foods);

- pharmacological measures, drug therapy (diuretics, ACE inhibitors or AT1 antagonists, aldosterone receptor antagonists, vasodilators and positive inotropic drugs digoxin);

- invasive intervention-heart transplantation (StepanovićPetrović and Micov, 2011).

\subsection{Effects and application of hawthorn drugs and phyto- preparations}

The EMA (2016b) monograph quotes only the traditional use of Crataegi folium cum flora in the form of crushed/pulverized herbal drugs and extractive preparations (dry and liquid extracts, tinctures, expressed juice from the fresh leaves and flowers.

- "Indication 1 - to mitigate symptoms of temporary nervous cardiac complaints (palpitations, perceived extra heartbeat due to mild anxiety) after serious conditions have been excluded by a medical doctor.

- Indication 2 - for relief of mild symptoms of mental stress and to aid sleep. The product is a traditional herbal medicinal product for use in specified indications exclusively based upon long-standing use."

According to the Commission E Crataegi folium cum flore is approved for indications and usage for the decrease in cardiac output (Stage II NYHA). Hawthorn can be used for senile heart, chronic cor pulmonale, and mild forms of bradycardia (Blumenthal, 1998; PDR, 2000).

Standardized extracts of hawthorn leaves and flowers (defined content of oligomeric procyanidins and/or flavonoids), or individual fractions (oligomeric procyanidins, flavonoids, biogenic amines) were used during in vivo performed experiments on animals or isolated organs, and the following pharmacological effects were confirmed (Bisset and Wichtl, 2001; Blumenthal, 1998; ESCOP, 2003; Hänsel et al., 1999; Petrović, 2003; Petrović and Kukić-Marković, 2008; Schulz et al., 2004):

- slight improvement in the contractility of the heart muscle, myocardium (positive inotropic effect - cardiotonic action)

- improving coronary blood flow with increasing myocardial tolerance to oxygen deficiency

- reduction of peripheral vascular resistance with the addition of mild antihypertensive effect 
- prolongation of the refractory period (negative bathmotropic effect) and potential antiarrhythmic effect

- accelerate the conduction of impulses in the myocardium (positive dromotropic effect)

- mild diuretic effect

- improving subjective symptoms and quality of life.

The effects of drugs and preparations of hawthorn fruit are similar to the effects of drugs and preparations of leaves and flowers (ESCOP, 2009).

It should be emphasized that hawthorn preparations are not specific drugs for acute disease treatment. They are primarily used as a preventive measure for milder forms of myocardial insufficiency (heart failure, hypertension, and arteriosclerosis of the elderly heart) (EMA, 2016a; Hänsel et al., 1999).

As it was previously mentioned, the active substances in hawthorn flowers, leaves, and fruits are procyanidins and flavonoids, but despite numerous studies, the mechanism of action of standardized hawthorn extracts has not been confirmed with certainty. Based on in vitro tests, possible mechanisms of action are indicated as:

- inhibition of cAMP-phosphodiesterase activity

- inhibition of $\mathrm{Na}^{+}-\mathrm{K}^{+}$-ATPase activity

- $\beta$-sympathomimetic activity

- inhibition on angiotensin-converting enzyme

- inhibition of thromboxane (TXA2) synthesis and stimulation of prostacyclin (PGI2) synthesis

- antioxidant and radical scavenging activities

- inhibition of the complement system

- inhibition of the human neutrophil elastase (ESCOP, 2003; 2009).

Arslan and Bektas (2018) reported in their study that the flavonoids of Crataegus spp. have a beneficial effect on thrombosis, so the preparations can be used as therapeutic agents in complementary medicine. Orhan (2019) pointed out that $C$. oxyacantha, in addition to its use in the treatment of various heart problems, including heart failure, angina pectoris, hypertension, mild changes in heart rhythm, atherosclerosis, also exhibits antihyperlipidemic, anxiolytic, immunomodulatory, and antimutagenic effects. Tadić et al. (2008) have been proved anti-inflammatory, gastroprotective, free-radical-scavenging, and antimicrobial activities of hawthorn berries ethanol extract. Ljubuncic et al. (2005) reported the antioxidant activity of the Crataegus aronia (syn. C. azarolus L.), where a watersoluble decoction was made from the leaves and unripe fruits of the plant, and possessed substantial antioxidant activity as a result of its ability to inhibit oxidation of $\beta$-carotene, lipid peroxidation in rat liver, due to its efficient free radical scavenging activity. Halver et al. (2019) reported positive effects of Crataegus extracts on heart muscle after ischemic injury and their potential contributions to cardiopoietic differentiation of stem cells. These in vitro data could be valuable for potential therapeutic heart regeneration after myocardial infarction. Niederseer et al. (2019) demonstrated positive comparable effects of Crataegus extract and Nordic walking on endothelial function and lipid profile in healthy overweight individuals.

\section{CLINICAL STUDIES OF EFFICACY}

The results of clinical studies are reported mainly for two dry extracts of hawthorn leaves and flowers (ethanol $45 \% \mathrm{v} / \mathrm{v}$ and methanol $70 \% \mathrm{v} / \mathrm{v}$; drug/extract ratio 4-6.6(7):1):
- Crategus extract WS 1442 standardized to $18.75 \%$ oligomeric procyanidins calculated as epicatechin and

- Crategus extract LI 132 standardized to $2.2 \%$ flavonoids calculated as hyperoside (Holubarsch et al., 2018; Petrović, 2003; Zorniak et al., 2017).

EMA (2016a), ESCOP (2009), WHO (2002) monographs, Schulz et al. (2004) and Zorniak et al. (2017) reported results from studies (randomized, double-blind, placebo-controlled, and multicentre clinical study), where patients with chronic HF, NYHA class II-III were treated. Patients in addition to standard therapy received an ethanolic dry extract from hawthorn leaves and flowers named WS 1442.

The therapeutic efficacy of standardized hawthorn extract has been studied in several clinical studies (during the period of 1987-2014) (EMA, 2016a; ESCOP, 2003; WHO, 2002). Studies (13 in the specified period), have shown significantly more efficiency of standardized extracts compared to placebo. The extracts (different doses 160 to $1800 \mathrm{mg}$ ) led to significant improvement in clinical symptoms of HF (increased tolerance to physical exertion, increased ejection fraction of the heart, decreased incidence of dyspnea, cough, and palpitations fatigue, ankle edema, blood pressure, heart rate). Patient groups with modest LVEF (damage of left ventricular ejection fraction) had the improvement when receiving the extract and potential reduction of sudden cardiac deaths in patients with less compromised left ventricular function was reported. In studies when dose dependence on the efficacy was investigated, the higher extract dose showed increased exercise tolerance. Results of several studies, as described in the above monographs, which studied the efficacy and safety of WS 1442 extract, in different doses and compared to placebo, showed a significant improvement in blood pressure, heart rate, as well as mental and physical stabilization of patients. In all studies, hawthorn extract was assessed as safe. According to EMA (2016a) and ESCOP (2003), significant improvement in clinical symptoms during the ergometric test and aerobic endurance training was showed in patients who received extract.

Based on the results of previously mentioned studies, it was concluded that the general symptoms of a patient with early chronic HF were less pronounced in patients who received extract compared to placebo.

Results of the controlled studies summarized in EMA (2016a) and ESCOP (2003), showed that the therapeutic effect of LI 132 extract is equivalent to that of ACE inhibitor captopril. Regarding the clinical trial of hawthorn fruit, as it is described in ESCOP (2009), it was reported that in controlled studies, which examined 3 different preparations of hawthorn fruit, where 24 healthy volunteers and 271 patients were involved, a positive effects on the cardiovascular system in healthy volunteers, increased exercise time in patients with congestive HF (NYHA II) and significantly improved exercise tolerance in patients were achieved.

General conclusions about clinical efficacy, according to the McMurray et al. (2012), the indications specified in the previously mentioned clinical trials, and the reported use for hawthorn extract cannot be regarded as proven by the available data.

Conventional treatment protocols for HF have undergone modifications during the last 15-20 years but till today fundamental therapy is ACE inhibitors (or angiotensin receptor blockers), beta-blockers, and a mineralocorticoid receptor antagonist and could be considered in every patient (NYHA II-IV). They are commonly used together with a diuretic given to relieve the symptoms and signs of congestion (McMurray et al., 2012).

Monotherapy or therapy with hawthorn products is not foreseen. The existing studies concerning the efficacy of hawthorn 
monotherapy have to be evaluated very critically. However, the goals of treatment should be to relieve symptoms and signs (e.g. edema), to prevent hospital admission, and to improve survival.

Taken together, the results of all previously in detail explained studies were the basis for the well-established use indications. According to the new guidelines hawthorn preparations are not recommended as monotherapy in heart failure. Previously mentioned studies investigated only surrogate parameters (ergometer capacity, pressure-rate product etc.), which is no longer enough to current knowledges and corresponding guidelines (McMurray et al., 2012). Nowadays, it is advise that hawthorn be the part of adjunctive therapy for heart failure.

\subsection{Pharmacokinetics}

According to the available literature, studies of the flavonoids and oligomeric procyanidins bioavailability in the human population are not available to the best of our knowledge. Studies were performed on mice using radioactive ${ }^{14} \mathrm{C}$-labeled catechin, oligomeric procyanidins, as well as the proportion of total procyanidins. It was concluded that a significant proportion of oligomeric procyanidins (over $50 \%$ ) were resorbed and distributed to tissues for a relatively long time and eliminated by urine (ESCOP, 2003; Hänsel et al., 1999).

\section{PHYTOPREPARATIONS}

The hawthorn leaf and flower, as well as the fruit, could be used in the form of a tea as a decoction, liquid extract and tincture (herbal drops), dry extract (capsules, tablets), and as fresh juices. Phytopreparations of leaves, flowers, and fruits are intended to be adjunctive therapy for heart failure. Rote Liste (2007) within the section "Cardiaka-Cardioactive plants" lists 41 monocomponent and 6 combined preparations containing hawthorn extracts. These are mainly solid galenic forms (capsules, coated tablets) where the content of dry extract leaves and flowers of hawthorn (4-7(6.6):1) per single dose ranged from $80 \mathrm{mg}$ to $600 \mathrm{mg}$. The most often used extraction agent is ethanol in various concentrations, less often methanol. Rote Liste (2007) prescribed water liquid extractherbal drops, juices made from fresh leaves with flowers, as well as hawthorn fruits. In the combined preparations, in addition to hawthorn, the extracts of lemon balm, valerian, olive, and passionflower are also present in the group of cardiac. Rote Liste (2020) in the section "Cardioactive plants" lists a total of 15 monocomponent and 1 combined preparation containing hawthorn extracts. They are also mainly solid galenic forms as well as different liquid forms previously described. Today, the amount of dry extract, the drug/extract ratio, and the extraction agent are increasingly stated in the preparation declaration.

The hawthorn fruit is not used for tea making. Fruit extracts (standardized to oligomeric procyanidins or flavonoids) are used exclusively for the production of phytopreparations, mainly in combination with standardized leaf and flower extracts. The fruit is used to make phytopreparations based on fresh fruit juice. The European Medicines Agency states that hawthorn is most often combined with Valerianae radix, Passiflorae herba, Viscum album herba, Menthae folium, Melissae folium, Hyperici herba, Matricariae flos, Salix cortex, vitamin E, and minerals (EMA, 2016a).

On the domestic and foreign markets, there are preparations for alleviating the problems of the cardiovascular system, which include appropriate herbal drugs derived from the following medicinal plants: hawthorn, garlic, lemon balm, valerian, motherwort, grapes, green tea, ginseng, sage, olive, mistletoe, rosemary, artichoke, blueberry, etc.
According to Bisset and Wichtl (2001), the hawthorn as a drug, but more especially extracts prepared from it, are present in more than 100 prepared remedies, particularly in the groups of cardiotonics, coronary remedies, and antihypertonis, as well as preparations with iron, tonics, arteriosclerosis remedies, etc. Products containing only Crataegus extracts are usually standardized based on their oligomeric procyanidins content as Crataegutt ${ }^{\circledR}$, Eurython ${ }^{\circledR}$, or adjusted to a given flavonoid content, e.g. Esbericard ${ }^{\circledR}$, Cratamed ${ }^{\circledR}$, Oxacant ${ }^{\circledR}$, Melicedin $\AA$, etc. The number of preparations that contain hawthorn extracts in combination with other drug extracts is much larger.

\subsection{Dosage}

The recommended daily dose of hawthorn leaves and flowers dry extract ( $45 \%$ ethanol or $70 \%$ methanol, and the ratio of drug to extract 4-7:1) is $160-900 \mathrm{mg}$, with a defined content of oligomeric procyanidins (30-168.7 mg, calculated as epicatechin) and flavonoids (3.5-19.8 mg, calculated as hyperoside according to DAB 10 (1993)), divided into 2 or 3 single doses. Based on recent clinical findings, the highest therapeutic efficacy was achieved with a daily dose of $600-900 \mathrm{mg}$ of dry extract. Usage is recommended for at least 6 weeks (Blumenthal, 1998; ESCOP, 2003; Hänsel et al., 1999; Schulz et al., 2004; WHO, 2002).

According to the EMA monograph (EMA, 2016b), tea preparation can be made from hawthorn leaves and flowers (1-2 $\mathrm{g}$ of the comminuted herbal substance in $150 \mathrm{~mL}$ of boiling water as an herbal infusion up to 4 times daily). Dry extract (DER 4-7: 1), extraction solvent: methanol $70 \% \mathrm{v} / \mathrm{v}$ or dry extract (DER 4-7.1:1), extraction solvent: ethanol 45-70 \% v/v in single dose: $80-300 \mathrm{mg}$, daily dose: $240-900 \mathrm{mg}$ or single dose: $80-450$ $\mathrm{mg}$, daily dose: $240-900 \mathrm{mg}$, respectively. The extracts are not standardized on the active ingredients, but the solvent and the drug/extract ratio are important. According to WHO (2002) and ESCOP (2003) monographs, recommended single doses of hawthorn leaves and flowers are 1-1.5 g, 3-4 times daily. According to ESCOP (2009) recommended single dose of powdered hawthorn berries is $0.3-1 \mathrm{~g}$, three times daily.

\subsection{Safety of phytopreparation application}

\subsubsection{Safety precautions}

Before using herbal drugs or appropriate phytopreparations, an accurate diagnosis of stage II congestive HF should be made. Medical attention is necessary if the pain occurs in the area of the heart, spreads to the arms, upper abdomen, or neck area, or in cases of respiratory distress (e.g. dyspnea) (EMA, 2016a; WHO, 2002).

In therapeutic doses, hawthorn preparations do not lead to side effects. Adverse reactions are rare, and Yusuf and Mericli (2016) reported that in a clinical study involving 5577 subjects, the efficacy of two standardized hawthorn leaf and flower extracts (18.75\% oligomeric procyanidins and $2.25 \%$ flavonoids) at a daily dose of 160-1800 mg, over 324 weeks, reported 166 mostly mild to moderate side effects such as dizziness, nausea, headache, palpitation. No interactions with other drugs have been reported. Contraindications are not known so far. As EMA (2016b) states, the dry extract (DER 4-6.6:1, ethanol $45 \% \mathrm{~m} / \mathrm{m}$ ) did not indicate any genotoxicity in several in vivo and in vitro tests. Adequate tests on carcinogenicity and impaired fertility have not been performed yet.

\subsubsection{Pregnancy and breastfeeding}

Due to the impossibility of conducting study in this group of subjects, and therefore the lack of data availability, in accordance with the general medical practice related to pregnant and lactating women, these preparations should not be taken without consulting a doctor (EMA, 2016b). 


\subsubsection{Pediatrics}

Due to the absence of clinical and literature data, its use in children under 12 years of age is not recommended (EMA, 2016b).

\section{CONCLUSION}

The hawthorn leaf, flower, and fruit have a long history in the traditional medicine of many nations. Hawthorn leaves with flower and fruit, as well as hawthorn phytopreparations have been studied detailed from the aspect of the chemical structure and pharmacological action. Many controlled and uncontrolled clinical studies have been performed, and have demonstrated a beneficial effect on heart problems. According to the new guidelines hawthorn preparations are not recommended as monotherapy in heart failure. Herbal drugs and hawthorn preparations are used as adjunctive therapy for heart failure, and according to the EMA monograph to alleviate nervous heart problems (heart palpitations due to mild anxiety and to alleviate mild symptoms of mental stress).

\section{FUNDING}

This work was supported by the Ministry of Education, Science and Technological Development of the Republic of Serbia [Grant No. 451-03-68/2020-14/200003]

\section{REFERENCES}

AHA (1994). American Heart Association (AHA) medical/scientific statement. 1994 revisions to classification of functional capacity and objective assessment of patients with diseases of the heart, Circulation 90(1): 644-645.

Alirezalu, A., Ahmadi, N., Salehi, P., Sonboli, A., Alirezalu, K., Mousavi Khaneghah, A., Barba, F. J., Munekata, P. E. and Lorenzo, J. M. (2020). Physicochemical characterization, antioxidant activity, and phenolic compounds of hawthorn (Crataegus spp.) fruits species for potential use in food applications, Foods 9(4): 436.

Arslan, R. and Bektas, N. (2018). Potential antithrombotic effect of Crataegus species, Indian Journal of Pharmaceutical Education and Research 52(4s): S155-S157.

Bisset, N. and Wichtl, M. (eds) (2001). Herbal Drugs and Phytopharmaceuticals, Medpharm GmbH Scientific Publishers, Stuttgart.

Blumenthal, M. (ed.) (1998). The Complete German Commission E Monographs. Therapeutic Guide To Herbal Medicines, American Botanical Council, Austin, Texas.

Bradley, P. (ed.) (2006). British Herbal Compendium - A Handbook of Scientific Information on Widely Used Plant Drugs, Vol. 2, British Herbal Medicine Association, Bournemouth.

Cloud, A., Vilcins, D. and McEwen, B. (2020). The effect of hawthorn (Crataegus spp.) on blood pressure: A systematic review, Advances in Integrative Medicine 7(3): 167-175.

DAB 10 (1993). Deutscher Pharmacopoea. Deutsches Arzneibuch, 10 edn, Stuttgart: Deutscher Apotheker Verlag. $3^{\text {rd }}$ suppl.

Djordjevic, S. (2017). From medicinal plant raw material to herbal remedies, in H. El-Shemy (ed.), Aromatic and Medicinal Plants - Back to Nature, In Tech, Rijeka, pp. 169-217.

Dokumacı, Y. K., Uslu, N., Hacıseferoğulları, H. and Örnek, M. N. (2021). Determination of some physical and chemical properties of common hawthorn (Crataegus monogyna Jacq. var. monogyna), ErwerbsObstbau 63(1): 99-106.

Edwards, J. E., Brown, P. N., Talent, N., Dickinson, T. A. and Shipley, P. R (2012). A review of the chemistry of the genus Crataegus, Phytochemistry 79: 5-26.

EMA (2016a). Assessment report on Crataegus spp., folium cum flore, European Medicines Agency, Committee on Herbal Medicinal Products (HMPC), Report No.:EMA/HMPC/159076/2014, London.

EMA (2016b). European Union herbal monograph on Crataegus spp., folium cum flore, European Medicines Agency, Committee on Herbal Medicinal Products (HMPC), Report No.:EMA/HMPC/159075/2014, London.
ESCOP (2003). The Scientific Foundation for Herbal Medicinal Products, $2^{\text {nd }}$ edn, ESCOP Monographs, European Scientific Cooperative on Phytotherapy, Devon and Thieme, Stuttgart and New York.

ESCOP (2009). The Scientific Foundation for Herbal Medicinal Products, $2^{\text {nd }}$, supplement 2009 edn, ESCOP Monographs, European Scientific Cooperative on Phytotherapy, Devon and Thieme, Stuttgart and New York

Halver, J., Wenzel, K., Sendker, J., Carrillo García, C., Erdelmeier, C. A. J. Willems, E., Mercola, M., Symma, N., Könemann, S., Koch, E., Hensel, A. and Schade, D. (2019). Crataegus extract WS®1442 stimulates cardiomyogenesis and angiogenesis from stem cells: A possible new pharmacology for hawthorn?, Frontiers in Pharmacology 10: 1357.

Hänsel, R., Sticher, O. and Steinegger, E. (1999). Pharmakognosie - Phytopharmazie, Springer-Lehrbuch, Springer Berlin Heidelberg, Berlin, Heidelberg.

Holubarsch, C. J. F., Colucci, W. S. and Eha, J. (2018). Benefit-risk assessment of Crataegus extract WS 1442: An evidence-based review, American Journal of Cardiovascular Drugs 18(1): 25-36.

Jančić, R. and Lakušić, B. (2017). Botanika Farmaceutika, Lento, Belgrade.

Josifović, M. (ed.) (1972). Flora of Republic of Serbia, Vol. IV, Serbian Academy of Sciences and Art, Belgrade.

Kaul, R. (1998). Der Weißdorn: Botanik, Inhaltsstoffe, Qualitätskontrolle, Pharmakologie, Toxikologie und Klinik, Wissenschaftliche Verlagsgesellschaft $\mathrm{mbH}$, Stuttgart.

Konjević, R. and Tatić, B. (2006). Plant names dictionary, NNK Internacional, Belgrade.

Kovačević, N. (2002). Pharmacognosy Basics, Srpska školska knjiga, Belgrade.

Kumar, D., Arya, V., Bhat, Z. A., Khan, N. A. and Prasad, D. N. (2012). The genus Crataegus: chemical and pharmacological perspectives, Revista Brasileira de Farmacognosia 22(5): 1187-1200.

Lanzara, P. and Pizzetti, M. (1982). Trees, Mladinska knjiga, Ljubljana.

Ljubuncic, P., Portnaya, I., Cogan, U., Azaizeh, H. and Bomzon, A. (2005) Antioxidant activity of Crataegus aronia aqueous extract used in traditional Arab medicine in Israel, Journal of Ethnopharmacology 101(13): 153-161.

Lund, J. A., Brown, P. N. and Shipley, P. R. (2020). Quantification of North American and European Crataegus flavonoids by nuclear magnetic resonance spectrometry, Fitoterapia 143: 104537.

McMurray, J. J., Adamopoulos, S., Anker, S. D., Auricchio, A., Böhm, M. Dickstein, K. and et al. (2012). ESC Guidelines for the diagnosis and treatment of acute and chronic heart failure 2012: The Task Force for the Diagnosis and Treatment of Acute and Chronic Heart Failure 2012 of the European Society of Cardiology. Developed in collaboration with the Heart Failure Association (HFA) of the ESC, European Heart Journal 33(14): 1787-1847.

Muradoğlu, F., Gürsoy, S. and Yıldız, K. (2019). Quantification analysis of biochemical and phenolic composition in hawthorn (Crataegus spp.) fruits, Erwerbs-Obstbau 61(2): 189-194.

Niederseer, D., Ledl-Kurkowski, E., Kvita, K., Funk, P. and Niebauer, J. (2019). Safety and effects of Crataegus extract WS 1442 and Nordic walking on lipid profile and endothelial function: A randomized, partially blinded pilot study in overweight volunteers, Acta Clinica Croatica 58(4): 604-614.

Orhan, I. E. (2019). Phytochemical and pharmacological activity profile of Crataegus oxyacantha L. (hawthorn) - A cardiotonic herb, Current Medicinal Chemistry 25(37): 4854-4865.

PDR (2000). Physician's Desk Reference (PDR) for Herbal Medicines, Medical Economics Company, Montvale, New Jersey.

Petrović, S. (2003). The use of hawthorn preparations in treatment of heart failure, Arhiv za farmaciju 53(5): 373-385.

Petrović, S. and Kukić-Marković, J. (2008). Herbal and traditional medicines for treatment of cardiovascular system disorders, Arhiv za farmaciju 58(5-6): 419-431.

PF X (1982). Pharmacopée française, $10^{\text {th }}$ edn, Adrapharm, Paris.

Ph. Eur. (2014a). European Pharmacopoeia, Vol. 8.1, Council of Europe, Strasbourg. 01/2010:1432.

Ph. Eur. (2014b). European Pharmacopoeia, Vol. 8.1, Council of Europe, Strasbourg. 04/2013:1220.

Ph. Eur. (2014c). European Pharmacopoeia, Vol. 8.1, Council of Europe, Strasbourg. 01/2010:1865.

Ph. Eur. (2014d). European Pharmacopoeia, Vol. 8.1, Council of Europe, Strasbourg. 01/2008:1864. 
Ph. Helv. VIII (1997). Pharmacopoea helvetica, $8^{\text {th }}$ edn, Département fédéral de l'intérieur, Berne.

Rote Liste (2007). Arzneimittelverzeichnis für Deutschland, Rote Liste Service $\mathrm{GmbH}$, Frankfurt/Main.

Rote Liste (2020). Arzneimittelverzeichnis für Deutschland, Rote Liste Service $\mathrm{GmbH}$, Frankfurt/Main.

Sagaradze, V. A., Babaeva, E. Y., Ufimov, R. A., Trusov, N. A. and Kalenikova, E. I. (2019). Study of the variability of rutin, vitexin, hyperoside, quercetin in "Crataegi folium cum flore" of hawthorn (Crataegus L.) species from Russian flora, Journal of Applied Research on Medicinal and Aromatic Plants 15: 100217.

Sarić, M. (ed.) (1986). Flora of SR Serbia, Vol. X of Supplement to the Flora of SR Serbia with new data on plant species, Serbian Academy of Sciences and Arts, Belgrade.

Sarić, M. (ed.) (1989). Medicinal Plants of SR Serbia, Serbian Academy of Sciences and Arts, Belgrade.

Schulz, V., Hänsel, R., Blumenthal, M. and Tyler, V. E. (2004). Rational Phytotherapy, Springer Berlin Heidelberg, Berlin, Heidelberg.

Šilić, Č. (1990). Atlas of Trees and Shrubs, IP Svjetlost, Institute for textbooks and teaching aids, Sarajevo and Belgrade.

Simonović, D. (1959). Botanical Dictionary, Plant Names, Naučno delo, SANU, Belgrade.

Stepanović-Petrović, R. and Micov, A. (2011). Therapy of heart failure, in N. Ugrešić (ed.), Pharmacotherapy for pharmacists, Faculty of Pharmacy, University of Belgrade, Belgrade, p. 79-103.

Stojanović, V. (ed.) (2013). Handbook for the collection of protected wild species of plants, animals and fungi, Institute for Nature Conservation of Serbia, Belgrade.

Tadić, V. M., Dobrić, S., Marković, G. M., Đorđević, S. M., Arsić, I. A., Menković, N. R. and Stević, T. (2008). Anti-inflammatory, gastroprotective, free-radical-scavenging, and antimicrobial activities of hawthorn berries ethanol extract, Journal of Agricultural and Food Chemistry 56(17): 7700-7709.

Tasić, S., Šavikin, K. and Menković, N. (2009). A Guide Through the World of Medicinal Herbs, Alexandria, Belgrade.

Tassell, M. C., Kingston, R., Gilroy, D., Lehane, M. and Furey, A. (2010). Hawthorn (Crataegus spp.) in the treatment of cardiovascular disease, Pharmacognosy Reviews 4(7): 32-41.

Tucakov, J. (1996). Herbal treatment - Phytotherapy, Prosveta, Belgrade.

Tutin, T., Heywood, V., Burges, N., Moore, D., Valentine, D., Walters, S. and Webb, D. (eds) (1968). Flora Europaea, Vol. 2, Cambrige University Press, London.

WHO (2002). Folium cum Flore Crataegi, WHO monographs on selected medicinal plants, Vol. 2, World Health Organization, pp. 66-82.

Yang, B. and Liu, P. (2012). Composition and health effects of phenolic compounds in hawthorn (Crataegus spp.) of different origins, Journal of the Science of Food and Agriculture 92(8): 1578-1590.

Yusuf, J. B. and Mericli, A. H. (2016). Pharmacological activities of Crataegus species: A review, Journal of Multidisciplinary Research and Development 3(4): 73-76.

Zorniak, M., Szydlo, B. and Krzeminski, T. F. (2017). Crataegus special extract WS 1442: Up-to-date review of experimental and clinical experiences, Journal of Physiology and Pharmacology 68(4): 521-526. 